\title{
MAMÁ, QUIERO SER "TRONISTA". EL PODER DE LA PROGRAMACIÓN TELEVISIVA EN ADOLESCENTES
}

\author{
Laura Gorjón Palos \\ Educadora Social \\ Ana Isabel Isidro de Pedro \\ Profesora Titular de E.U. Departamento de Psicología Social y Antropología. \\ Universidad de Salamanca. Email: anyis@usal.es \\ https://doi.org/10.17060/ijodaep.2017.n1.v2.951
}

Fecha de Recepción: 27 Marzo 2017

Fecha de Admisión: 1 Abril 2017

\section{RESUMEN}

Los medios de comunicación han cobrado gran importancia como agente socializador, forjando y transmitiendo identidades a través de imágenes y discursos, de tal modo que influyen, de manera inmediata y cotidiana, en las conductas y actitudes de los espectadores. Y uno de esos medios, tan profundamente arraigado en nuestras costumbres cotidianas que difícilmente podemos desprendernos de su consumo y del poder que ejerce sobre nosotros, es la televisión (convencional 0 visionada a través de internet). La competencia de las cadenas televisivas y la feroz lucha por la audiencia han llevado a un cambio en la programación, de tal manera que, en la actualidad, un porcentaje importante de la parrilla lo constituyen los denominados programas basura, entre los que no son ajenos aquéllos que exhiben prejuicios y estereotipos de género.

Este trabajo pretende examinar los productos televisivos consumidos por los adolescentes y el impacto e influencia que tienen en ellos los denominados "reality shows". Para ello se utilizó un cuestionario de elaboración propia de 36 ítems (con preguntas abiertas, cerradas y tipo Likert), que fue aplicado a una muestra de 237 sujetos de entre 14 y 23 años. Tras analizar, agrupar, contrastar e interpretar los datos, constatamos que el consumo de televisión entre los sujetos de la muestra es masivo y cotidiano $(99,4 \%)$, así como los comentarios al respecto en las redes sociales. De igual manera, un $73 \%$ de los sujetos manifiesta ser seguidor de, al menos, un reality show, una mayoría $(87,3 \%)$ encuentra importantes ventajas al hecho de salir en televisión, a un $35 \%$ les gustaría ser personas relacionadas con la fama y a un sorprendente $27 \%$ les gustaría participar en un reality show. Los resultados muestran la necesidad de una educación para el consumo de los productos televisivos que ponga el énfasis en el papel reflexivo y crítico del espectador.

Palabras clave: Televisión basura; Reality show, Espectador 


\section{MAMÁ, QUIERO SER “TRONISTA”. EL PODER DE LA PROGRAMACIÓN TELEVISIVA EN ADOLESCENTES}

\section{ABSTRACT \\ Mommy, I want to be a reality show contestant. The power of the television programming in adolescents}

The media have gained great importance as a socializing agent, building up and transmitting identities through images and speeches, in such a way that they influence, immediately and daily, the behaviors and attitudes of the spectators. One of those media, so deeply rooted in our daily habits that we can hardly detach from both its consumption and the power that it exerts on us, is television (conventional or through Internet). The competition between the television networks and the terrible fight for the audience have led to a change in the programming, in such a way that, at present, a significant percentage of the guide is constituted by the so-called trash TV programs, among which are those exhibiting prejudices and gender stereotypes.

This paper aims for examine the television products consumed by adolescents and the impact and influence that the so called "reality shows" have. To do this, a homemade questionnaire of 36 items (with open, closed and Likert-type questions) was used on a sample of 237 subjects, aged between 14 and 23 years old. After data analyzing, grouping, contrasting and interpreting, it was found that television consumption among the subjects of the sample was massive and daily $(99.4 \%)$, as well as the related comments on the social networks. Similarly, $73 \%$ of the subjects claimed to be a follower of at least one reality show, most of them (87.3\%) found important advantages to the fact of going out on TV, 35\% would like to be people related to fame and a surprising $27 \%$ would like to participate in a reality show. The results show the necessity of an education for the television products consumption that put the emphasis on the reflective and critical role of the spectator.

Keywords: Trash television; Reality show; Spectator

\section{INTRODUCCION}

Este trabajo responde al desasosiego que produce un hecho tan inquietante como ampliamente constatable entre nuestros niños, adolescentes y jóvenes. Ahora los niños ya no quieren ser astronautas, bomberos, peluqueros o médicos. Cuando una niña responde a la pregunta "¿qué quieres ser de mayor?", con un lacónico y convencidísimo "quiero ser tronista", cualquier persona cabal se preguntaría inmediatamente "¿Y qué profesión es ésa?”, pero otros muchos sí saben a qué se refiere.

A continuación intentaremos ahondar en el fenómeno de la influencia de la programación televisiva en las actitudes, los valores y los comportamientos de las personas. Concretamente, el poder que ejerce la "telebasura" sobre adolescentes y jóvenes, centrándonos en el reality show que es objeto de la respuesta (real) de la niña de 12 años antes aludida ("Mujeres y Hombres y Viceversa"), programa que, asombrosamente, lleva ya cumplidos 9 años de exitosa emisión televisiva diaria.

Como ya se defendió previamente (Isidro, 2008):

En la actualidad sobran bombardeos iconográficos insustanciales, programas televisivos vacuos -ahora llamados magacines- o reclamos mediáticos banales donde adalides del histrionismo, investidos del rimbombante marbete de "contertulios" o, peor aún, jintelectuales! (hoy cualquiera detenta este mérito), opinan sin sonrojo tanto de las soluciones taumatúrgicas a la recesión económica como de los devaneos amorosos de tristes personajillos, de las evoluciones de los participantes en tal 0 cual concurso insufrible 0 , si se tercia, de las últimas aportaciones en el campo de la Física Cuántica. Trivialidades estériles de contenido y conocimiento pero hábiles captadoras de un público adocenado que no quiere pensar. $Y$ tal vez nos falten productos serios, hilados por la solidez intelectual de unos autores ilustrados, profesionales y fidedignos. Posiblemente a muchos les resulte 
más cómodo y atractivo aquello, pero otros (quiero pensar que bastantes) disfrutamos con el placer intelectual que nos aporta, por ejemplo, la lectura de textos rigurosos y cabales. (Isidro, 2008, s.p.)

Qué duda cabe que la televisión supone una ventana al mundo: emite mensajes, significados e intencionalidades y exhibe vidas ajenas y modos de vivirlas. Y los espectadores, lejos de permanecer ajenos a su influencia, son cautivados por su seducción, tan sutil como poderosa. Así, se convierte en transmisora de actitudes, valores y patrones de comportamiento. En definitiva, de modelos de vida para lo bueno y para lo malo. Porque, como afirman Del Río Álvarez y Del Río (2004), la televisión ejerce su influencia tanto en las virtudes como en los defectos de todos nosotros.

Y más en un público adolescente, que se encuentra en una etapa crucial para la construcción de su identidad y su personalidad.

Desde los años ochenta han cobrado un auge sin precedentes los programas denominados "telebasura" y el morbo que éstos conllevan. Ante quienes defienden que la audiencia sabe lo que quiere, es soberana y, por tanto, el único filtro en la selección y emisión de contenidos ha de ser la demanda de aquélla, no han faltado otras voces críticas que se alzan para cuestionar airadamente este tipo de programación, considerándola inadecuada y perniciosa no solo para los telespectadores adultos sino, especialmente, para los más jóvenes y abogando por la calidad televisiva y por programas de contenido educativo y cultural. Pero, ¿qué tipo de programación prefieren los jóvenes?, ¿la audiencia demanda libremente tales programas o son éstos los que, hábilmente, saben cómo enredar al incauto espectador, que se cree más invulnerable de lo que realmente es?

De entre la "telebasura", merecen especial consideración los reality shows, un género que, desde la pionera edición de "Gran Hermano", allá por 1999, acostumbra a copar las parrillas, siendo frecuentemente líderes de audiencia.

Y uno de los más exitosos es "Mujeres y Hombres y Viceversa", donde diferentes jóvenes se van conociendo para así encontrar el amor. Qué duda cabe que en la práctica, ese romántico -y hasta loable- fin queda empañado por otras motivaciones bastante más pedestres y ramplonas.

En el programa se hace gala continuamente de diversos prejuicios, estereotipos, mitos románticos, etc. que "tronistas" (aquéllos a quienes van a pretender o conquistar el resto de concursantes), pretendientes, asesores del amor y público en general verbalizan con frecuencia.

Se pretende la meta de un amor romántico en el que la magia e irracionalidad implica incontrolabilidad y sufrimiento porque, de no ser así, no es verdadero amor. En el mismo sentido, se exhibe el mito romántico de los celos, es decir, la creencia de que éstos constituyen una condición esencial del verdadero amor y una muestra fehaciente del mismo.

En la misma línea, el mito del príncipe azul suele estar presente, sobre todo, en las "pretendientas", quienes frecuentemente lo verbalizan, apostillando que, como cualquier mujer, buscan a su príncipe azul, al hombre perfecto que está por ahí, esperando ser reconocido y encontrado e imaginando que existe para ellas ese hombre idealizado que las protegerá y cuidará y que solo a su lado encontrarán la felicidad. Esta idea es infantil, pueril y manifiestamente pasiva, ya que avala la idea de que la felicidad depende exclusivamente de otros o de encontrar la pareja ideal. El trasunto de esta creencia promueve tanto la dependencia y sumisión de la mujer (como ser frágil y débil que precisa la protección y la guía masculina) como el ejercicio del control por parte de los hombres.

A ello se une el mito de la media naranja, donde la persona considera que esa pareja ideal, complementaria y perfecta para ella, la llena de tal modo que sin esa persona, nos sentiremos incompletos e infelices. Obviamente, esta idea trasluce una supersimplificación de las personas solteras -especialmente de las mujeres- que no alcanzarán la plenitud, la dicha y la felicidad a no ser que tengan a alguien a su lado y genera expectativas poco realistas sobre las relaciones amorosas, dependencia afectiva y un enganche inapropiado. 


\section{MAMÁ, QUIERO SER “TRONISTA”. EL PODER DE LA PROGRAMACIÓN TELEVISIVA EN ADOLESCENTES}

Por otra parte, todos los concursantes exhiben una apariencia física extremadamente cuidada y un modo de vestir sugerente y hasta provocativo, constituyendo la imagen uno de los ingredientes fundamentales del programa, por no decir el único. En ningún momento participan personas con una figura menos estilizada y más realista (bien porque no "acuden" a encontrar el amor como concursantes 0 , más presumiblemente, porque en los castings previos son rechazados para participar). Esto tiene una doble interpretación: por un lado, se da a entender entre líneas que las personas con un físico menos atractivo, cuidado y cultivado no se pueden enamorar ni aspirar a ser lo felices que son las personas apuestas. Pero, por otra parte, revela que no es la persona en su conjunto lo que hay que valorar para determinar el grado de afinidad romántica con ella, sino que lo único importante es la apariencia, el atractivo físico y, por supuesto, la juventud que exhibe, frecuentemente cincelados a golpe de gimnasio o de bisturí.

Otro de los problemas que se manifiesta con toda su crudeza es que el fomento de la competitividad. En el transcurrir diario del programa y, de forma aún más ostensible, a la hora de realizar los retos entre los pretendientes, se aprecia profusamente que, lejos de fomentar el compañerismo, se alienta y jalea la competencia despiadada y el ataque encarnizado al otro. De tal forma que, con frecuencia, se compara a unos participantes con otros desde el punto de vista físico, dejando de lado cualquier ámbito educativo, intelectual, constructivo y personal. Todo vale para conseguir el fin propuesto y el maquiavelismo cobra todo su sentido.

De igual forma, se incurre en constantes inferencias. A menudo se encubren las propias carencias y vulnerabilidades sacando a colación numerosos cotilleos, rumores, chismes y bulos -tanto más jugosos cuanto más escabrosos- nada contrastados o manifiestamente falsos acerca de otros concursantes. Todos los presentes: pretendientes, "ganchos", "asesores del amor" y público en general conjeturan y deducen certezas a partir de informaciones incompletas, imperfectas, falaces 0 interesadas, que le han contado o que han llegado a sus oídos a través de terceras personas, dando pábulo a un estilo de comunicación teatralizada, retorcida y nada efectiva que deviene, en un sinfín de ocasiones, en sonados conflictos (espontáneos o provocados intencionalmente de manera hábilmente efectista).

Por todo ello, y a modo de resumen, la influencia potencial de este programa en los jóvenes es altamente significativa, ya que se fomenta una construcción errónea de la personalidad, de la identidad de género y de las relaciones interpersonales. Es manifiesta la presencia de estereotipos -especialmente de estereotipos de género- que alienta y promueve expectativas estereotipadas de los roles de género, ya que son profusas las diferencias forzadas entre hombres y mujeres (tanto evidentes como latentes) basadas, precisamente, en la magnificación de los roles de género, fraguando por ejemplo en todo momento la identidad femenina de "pibón" que por medio de sus encantos físicos conseguirá a su príncipe. Esto acrecienta la desigualdad de género y la dependencia y el control-de la relación y de la mujer- por parte del hombre.

De igual modo, normaliza las "parejas múltiples", puesto que presenta como apropiado y legítimo el flirteo simultáneo con las varias personas que integran el "escaparate" de la elección, elevándolo a la categoría de hazaña personal. Esta circunstancia no es lo habitual en la vida real ya que, en general, cuando se está conociendo a alguien con intención y deseo de tener una relación seria, no es frecuente que esa persona esté conociendo, al mismo tiempo, a más personas para, finalmente, quedarse con la mejor baza porque tal proceder no transmite confianza en el otro, mercantiliza a las personas, cosificándolas y equiparando la búsqueda de pareja a la elección de un producto. Asimismo, normaliza la deslealtad y la infidelidad, ya que en cuanto aparece un "mejor postor" no existe ningún reparo en aprovechar la situación.

Además, se promueve el valor de la inmediatez bajo el planteamiento, pueril e irreal, de que se 
pueden alcanzar las metas y los objetivos de manera tan rápida como fácil y sencilla. De este modo, se potencian los aspectos más superficiales, triviales y frívolos, al tiempo que se ningunea -y hasta se desprecia- el papel de la formación, el esfuerzo y el conocimiento en la consecución del éxito, el reconocimiento social, la fama e, incluso, el trabajo y el dinero, haciendo apología de la ignorancia y de la incultura.

Todo lo cual ratifica la aparición de nuevas expresiones, estilos de vestir, modas, etc., patrones de comportamiento, al fin y al cabo, así como creencias, actitudes y valores.

\section{OBJETIVO Y METODOLOGÍA}

El propósito de este trabajo es examinar los gustos, preferencias televisivas y el tipo de consumo televisivo que realizaran los jóvenes y conocer su impacto e influencia sobre ellos. Para ello, se ha realizado una investigación cuantitativa, elaborando y aplicando un cuestionario ad hoc, constituido por 36 ítems. Además de aquéllos ítems que recogen los datos sociológicos generales, se plantean preguntas abiertas y cerradas, así como algunas que siguen una escala tipo Likert. Dicho cuestionario fue aplicado a una muestra de 237 sujetos (160 mujeres y 77 hombres), entre 14 y 23 años, de Salamanca y provincia, estudiantes en centros públicos y concertados de $3^{0}$ y $4^{0}$ de Educación Secundaria Obligatoria, Bachillerato y Formación Profesional. El análisis fue realizado a partir de un contraste de resultados, a través del paquete estadístico SPSS.

\section{RESULTADOS}

Prácticamente todos los sujetos $(99,6 \%)$ afirman ver la televisión (excepto una chica, estudiante de F.P. que refiere no verla).

Refiriéndonos al tiempo diario medio que dedican a esta actividad, encontramos que la mayoría $(61,2 \%)$ pasa entre una y tres horas cada día frente al televisor, el $25,5 \%$ menos de una hora y el $13,9 \%$ supera las tres horas. Estas cifras evidencian, pues, un consumo importante que, en consecuencia, va en detrimento de otro tipo de actividades más activas y saludables a las que dedicar su ocio y tiempo libre.

Una amplia mayoría (el 68,8\%) considera que la programación televisiva es interesante, aduciendo motivos recurrentes como "Me parece interesante porque ponen cosas de la actualidad que a los adolescentes nos interesan", "Es interesante ya que aporta información". Sin embargo, algunos sujetos respondieron de manera opuesta a las opiniones mencionadas anteriores aduciendo, en general, a razones ligadas a la monotonía, tales como: "Siempre sale lo mismo en la televisión y ya me aburren".

Por lo que se refiere a los canales más demandados y consumidos por nuestros sujetos, los resultados son claros: Antena $3(55,7 \%)$ y Telecinco $(55,3 \%)$ se llevan la palma, seguidos de Divinity $(11 \%)$. Por contra, en el extremo opuesto, las cifras son ínfimas para canales con mayor contenido cultural y educativo, como es el caso de La $2(2,1 \%)$ o National Geographic $(0,8 \%)$.

Refiriéndonos específicamente a los realities, y ante la pregunta “¿Ves algún reality show?", el $73,0 \%$ de los chicos confiesa ser seguidor de uno o varios programas de este género, frente al $27 \%$ que afirman no ver ninguno. Al analizar este aspecto, no solo vemos que gran parte de los sujetos siguen al menos un programa televisivo de esta índole, sino que es de destacar la clara diferencia entre los alumnos de los centros públicos y los concertados a este respecto, ya que de ese $73 \%$ que manifiesta ser seguidor de algún reality, el $62,4 \%$ cursa estudios en centros públicos, frente al $37,6 \%$ que lo hace en centros concertados.

Sin embargo, cuando preguntamos acerca de cuáles son, concretamente, los realities que ven, hallamos datos contradictorios con la cifra global anterior, ya que solo el $19 \%$ reconoce no ver nin- 


\section{MAMÁ, QUIERO SER “TRONISTA". EL PODER DE LA PROGRAMACIÓN TELEVISIVA EN ADOLESCENTES}

guno. Aventuramos que esto podría deberse a que hay programas que algunos de los chicos no identifican como pertenecientes a este formato. Por su parte, el $28,3 \%$ se decantan por un solo reality de entre todos los que podrían ver y un nutrido 52,7\% reconoce ser espectador de dos o más.

Los más vistos son, por este orden, "Mujeres Hombres y Viceversa" (58,2\%), "Gran Hermano", (48,5\%), "Supervivientes" (30,4\%) y, más alejados, "Gandía Shore" (9,7\%), "Jersey Shore" (5,1\%), "Un príncipe para tres princesas" (4,2\%), "La Voz" $(4,2 \%)$, Adán y Eva $(3,0 \%)$, Pequín Express $(3,0 \%)$, "Casados a primera vista" $(2,1 \%)$, "Volverías con tu ex" (1,7\%), "Master Chef" $(1,3 \%)$ y con cifras aún menores $(0,8 \%)$, "Un príncipe para Corina", "Operación Triunfo" y "Top Chef”, respectivamente. Llaman la atención los exiguos niveles de audiencia que alcanzan entre los jóvenes de nuestra muestra los talent shows ("La Voz", "Master Chef", "Operación Triunfo" y "Top Chef”) frente a los realities más insustanciales.

Los motivos que más frecuentemente aducen para seguir programas de este tipo son: para entretenerse $(35,0 \%)$, por diversión $(13,9 \%)$, por curiosidad $(6,8 \%)$, por aburrimiento $(4,6 \%)$, porque otros lo ven (3,8\%), por descarte $(2,5 \%)$ o por encontrarlos al hacer zapping $(1,3 \%)$.

Constatamos que el programa "Mujeres y Hombres y Viceversa" es el reality más visto por nuestros sujetos y que, de entre quienes lo ven, un $61,2 \%$ lo hacen a través de la televisión convencional y un $38,8 \%$ lo ve a la carta a través de internet (lo cual exige una búsqueda activa del mismo).

Sondeando desde cuándo siguen el programa, la mayoría lo ve desde hace, al menos, dos años $(66,7 \%)$, seguido de quienes lo hacen desde entre uno y dos años $(16,0 \%)$, desde hace varias semanas $(9,3 \%)$ y, por último, desde hace unos días $(8,0 \%)$. Apreciamos, por tanto, que se trata de un público fiel con un seguimiento considerable en el tiempo.

Indagando en los motivos para ver "Mujeres y Hombres y Viceversa", encontramos que la gran mayoría $(75,5 \%)$ esgrimen que lo siguen para entretenerse, estando otras razones bastante alejadas: para distraerse $(11,0 \%)$, porque le gusta $(8,0 \%)$, porque les divierte $(4,2 \%)$ y por otros móviles diversos (1,3\%). A la luz de tales datos, parecerían evidenciarse importantes carencias en estos jóvenes a la hora de saber entretenerse y disfrutar de su tiempo libre y de ocio, ocupando su asueto en seguir programas de, cuanto menos, discutible gusto, calidad y ética.

Al analizar la influencia percibida del programa sobre su propia manera de ser, vestir, actuar 0 pensar, solo un 4,2\% de los sujetos ha respondido afirmativamente, es decir, consideran que el programa le influye personalmente; mientras que un $85,2 \%$ niega que el programa tenga algún tipo de influencia sobre él y un $10,6 \%$ reconoce que lo hace solo en ocasiones. No obstante, curiosamente el $73 \%$ de los jóvenes de la muestra se consideran suficientemente guapos para poder participar en el programa, frente a un $27 \%$ que dicen no sentirse lo suficientemente atractivos desde el punto de vista físico para poder ser participantes en el mismo. Por su parte, el $87,8 \%$ afirma que no se siente identificado con el programa, frente al 12,2\% que sí reconoce sentirse identificado. De acuerdo con estas cifras, parece que los jóvenes se consideran a sí mismos bastante invulnerables a la influencia de la programación televisiva, cosa que sabemos que no es cierta.

Al preguntarles si conocen qué son los prejuicios y los estereotipos, el 82,3\% responde afirmativamente, frente al $17,7 \%$ que reconoce no saberlo. Sin embargo, al vincular esos conceptos con el reality y preguntarles si creen que hay algún prejuicio o estereotipo en el programa, el 59,1\% afirma que sí existen, frente a solo el 1,2\% que asegura que no. Resulta curioso el dato que un $39,7 \%$ de los chicos confiesa no saber si existen o no prejuicios y estereotipos en el programa. Esto parece indicar que muchos sujetos de los que a priori sí creen saber qué son prejuicios y estereotipos no son, sin embargo, capaces de reconocerlos en la práctica.

Cuando se les pregunta, a propósito de la fama, si les gustaría ser famosos, el 65,0\% de los sujetos de la muestra responden negativamente y solo a un $35,0 \%$ sí les gustaría serlo. De entre los 
porqués para lo primero, la mayoría esgrime razones similares: "No quiero ser famoso porque eso implica no tener una vida privada", o "Porque no aguantaría la presión mediática". Sin embargo, las razones de los que sí desearían ser famosos van en la línea de: "Sí me gustaría ser famoso porque quiero saber lo que se siente y ganaría mucho dinero sin hacer nada" o "Sí me gustaría para tener una mejor vida".

En consonancia con estos datos, encontramos que un $73,0 \%$ declara que no participaría en un reality televisivo, frente a un $27,0 \%$ que manifiesta que sí lo haría. De éstos últimos, el 14,8\% quería participar en "Gran Hermano", el 5,5\% en "Mujeres Hombres y Viceversa" y "Supervivientes", respectivamente, $y$, con menor representación, en otros realities de tal jaez.

En consonancia con lo anterior, al preguntar acerca la importancia que le conceden a la privacidad en su vida, el $100 \%$ de los participantes afirma que la privacidad es relevante en todos los ámbitos de su vida. No obstante, cuando le preguntamos sobre el grado de importancia que tiene para ellos, apreciamos que para el $91,6 \%$ la privacidad es bastante importante o muy importante, entretanto que para el 8,5\% lo es poco, muy poco o les resulta indiferente (ver Tabla 1).

Tabla 1. En qué grado consideras importante tu privacidad

\begin{tabular}{|cl|c|c|}
\hline & Frecuencia & Porcentaje \\
\hline Válido & Muy poco & 1 &, 4 \\
& Poco & 3 & 1,3 \\
& Indiferente & 16 & 6,8 \\
Bastante & 55 & 23,2 \\
Mucho & 162 & 68,4 \\
Total & 237 & 100,0 \\
\hline
\end{tabular}

A propósito de la privacidad, les preguntamos sobre el uso de las redes sociales. Unánimemente, el 100\% refieren hacer uso cotidiano de manera activa de varias redes sociales. Y al respecto de la frecuencia con la que las usan, la gran mayoría $(89,5 \%)$ confiesa utilizarlas muy frecuentemente varias veces a lo largo del día.

Asimismo, encontramos que el $58,2 \%$ de los chicos afirman que comentan con sus amigos 0 familiares los contenidos, anécdotas 0 incidencias de este tipo de programas, frente al 41,8 que no lo hace.

\section{CONCLUSIONES}

Los medios de comunicación han cobrado tamaña importancia como agente socializador, colaborando y trasmitiendo identidades a través de imágenes y discursos. Los contenidos que visualizamos no son casuales sino que tienen intencionalidad, vida propia y ejercen un estudiado poder, ya que nos suministran continuamente puntos de vista, juicios, visiones particulares del mundo que nos rodea y principios morales que nos afectan mucho más de lo que creemos y de lo que estamos dispuestos a admitir. Y no solo respecto a aspectos triviales de nuestra vida sino que ejercen un gran poder de transformación sobre la manera de pensar, sentir, actuar y tratar con el entorno.

Por ello, es el espectador el que debe dotar de significado a la información que recibe, ya que todos los mensajes conllevan de forma implícita intencionalidades. Es el receptor el que "construye" el significado de la información pero, frecuentemente, es mucho más cómodo y descansado aceptar todo lo que nos es dado, sin que medie un cedazo crítico en su criba.

Para conseguir una televisión de calidad que promueva el desarrollo personal y social de los 


\section{MAMÁ, QUIERO SER “TRONISTA”. EL PODER DE LA PROGRAMACIÓN TELEVISIVA EN ADOLESCENTES}

sujetos no se puede tener en cuenta, exclusivamente, la ley de la oferta y la demanda sino que se han de facilitar y potenciar, sobremanera, la reflexión, la responsabilidad, la conciencia crítica, la actitud exigente y selectiva y la participación dinámica de los ciudadanos, promoviendo e impulsando la educación para un consumo -incluyendo el consumo televisivo- responsable y crítico.

\section{REFERENCIAS BIBLIOGRÁFICAS}

Del Río, P., Álvarez, A., y Del Río, P. (2004). Pigmalión: Informe sobre el impacto de la televisión en la infancia. Madrid: Fundación Infancia Aprendizaje.

Isidro, A. I. (2008). Con ciencia crítica. Manuscrito no publicado. 